\title{
DOG1 is commonly expressed in pancreatic adenocarcinoma but unrelated to cancer aggressiveness
}

\author{
Kristina Jansen ${ }^{1}$, Franziska Büscheck ${ }^{1}$, Katharina Moeller ${ }^{1}$, Martina Kluth ${ }^{1}$, Claudia Hube-Magg ${ }^{1}$, Niclas \\ Christian Blessin ${ }^{1}$, Daniel Perez ${ }^{1}$, Jakob Izbicki ${ }^{1}$, Michael Neipp ${ }^{2}$, Hamid Mofid ${ }^{3}$, Thies Daniels ${ }^{4}$, Ulf Nahrstedt ${ }^{5}$, \\ Christoph Fraune ${ }^{1}$, Frank Jacobsen ${ }^{1}$, Christian Bernreuther ${ }^{1}$, Patrick Lebok ${ }^{1}$, Guido Sauter ${ }^{1}$, Ria Uhlig ${ }^{1}$, \\ Waldemar Wilczak $^{1}$, Ronald Simon ${ }^{\text {Corresp., }}{ }^{1}$, Stefan Steurer ${ }^{1}$, Eike Burandt ${ }^{1}$, Andreas Marx ${ }^{1,6}$, Till Krech ${ }^{1,7}$, Till \\ Clauditz $^{1}$ \\ 1 University Medical Center Hamburg-Eppendorf, Hamburg, Germany \\ 2 Itzehoe Medical Center, Itzehoe, Germany \\ 3 Regio Clinic Pinneberg, Pinneberg, Germany \\ 4 Albertinen Hospital, Hamburg, Germany \\ 5 Schoen Clinic Hamburg Eilbek, Hamburg, Germany \\ ${ }^{6}$ Academic Hospital Fuerth, Fuerth, Germany \\ 7 Institute of Pathology, Clinical Center Osnabrueck, Osnabrück, Germany \\ Corresponding Author: Ronald Simon \\ Email address: r.simon@uke.de
}

Background. DOG1 (ANO1; TMEM16A) is a voltage-gated calcium-activated chloride and bicarbonate channel. DOG1 is physiologically expressed in Cajal cells, where it plays an important role in regulating intestinal motility and its expression is a diagnostic hallmark of gastrointestinal stromal tumors (GIST). Data on a possible role of DOG1 in pancreatic cancer are rare and controversial. The aim of our study was to clarify the prevalence of DOG1 expression in pancreatic cancer and to study its association with parameters of cancer aggressiveness.

Methods. DOG1 expression was analyzed by immunohistochemistry in 599 pancreatic cancers in a tissue microarray format and in 12 cases of pancreatitis on large tissue sections.

Results. DOG1 expression was always absent in normal pancreas but a focal weak expression was seen in 4 of 12 cases of pancreatitis. DOG1 expression was, however, common in pancreatic cancer. Membranous and cytoplasmic DOG1 expression in tumor cells was highest in pancreatic ductal adenocarcinomas (61\% of 444 interpretable cases), followed by cancers of the ampulla Vateri (43\% of 51 interpretable cases), and absent in 6 acinus cell carcinomas. DOG1 expression in tumor associated stroma cells was seen in 76 of 444 (17\%) pancreatic ductal adenocarcinomas and in 7 of 51 (14\%) cancers of the ampulla Vateri. Both tumoral and stromal DOG1 expression were unrelated to tumor stage, grade, lymph node and distant metastasis, mismatch repair protein deficiency and the density of CD8 positive cytotoxic T-lymphocytes in the subgroups of ductal adenocarcinomas and cancers of ampulla Vateri. Overall, the results of our study indicate that DOG1 may represent a potential biomarker for pancreatic cancer diagnosis and a putative therapeutic target in pancreatic cancer. However, DOG1 expression is unrelated to pancreatic cancer aggressiveness. 


\section{DOG1 is commonly expressed in pancreatic adenocarcinoma but unrelated to cancer aggressiveness}

Kristina Jansen ${ }^{1}$, Franziska Büscheck ${ }^{2}$, Katharina Möller ${ }^{2}$, Martina Kluth², Claudia Hube-Magg ${ }^{2}$, Niclas C Blessin ${ }^{2}$, Daniel Perez ${ }^{1}$, Jakob R Izbicki ${ }^{1}$, Michael Neipp ${ }^{3}$, Hamid Mofid ${ }^{4}$, Thies Daniels ${ }^{5}$, Ulf Nahrstedt ${ }^{6}$, Christoph Fraune ${ }^{2}$, Frank Jacobsen ${ }^{2}$, Christian Bernreuther ${ }^{2}$, Patrick Lebok ${ }^{2}$, Guido Sauter ${ }^{2}$, Ria Uhlig², Waldemar Wilczak ${ }^{2}$, Ronald Simon"\#, Stefan Steurer ${ }^{2}$, Eike Burandt $^{2}$, Andreas H Marx ${ }^{2,7}$, Till Krech ${ }^{2,8}$, Till S Clauditz ${ }^{2}$

${ }^{1}$ General, Visceral and Thoracic Surgery Department and Clinic, University Medical Center Hamburg-Eppendorf, Hamburg, Germany

2 Institute of Pathology, University Medical Center Hamburg-Eppendorf, Hamburg, Germany

${ }^{3}$ General, Vascular and Visceral Surgery Clinic, Itzehoe Medical Center, Itzehoe, Germany

${ }^{4}$ General, Visceral Thoracic and Vascular Surgery Clinic, Regio Clinic Pinneberg, Pinneberg, Germany

${ }^{5}$ General, Visceral and Tumor Surgery Clinic, Albertinen Hospital, Hamburg, Germany

${ }^{6}$ Department of General and Abdominal Surgery, Schoen Clinic Hamburg Eilbek, Hamburg, Germany

${ }^{7}$ Department of Pathology, Academic Hospital Fuerth, Fuerth, Germany

${ }^{8}$ Institute of Pathology, Clinical Center Osnabrueck, Osnabrueck, Germany

Corresponding Author:

Dr. Ronald Simon, Institute of Pathology, University Medical Center Hamburg-Eppendorf, Martinistr. 52, 20246 Hamburg, Germany

E-mail address: R.Simon@uke.de 


\section{Abstract}

33 Background. DOG1 (ANO1; TMEM16A) is a voltage-gated calcium-activated chloride and 34 bicarbonate channel. DOG1 is physiologically expressed in Cajal cells, where it plays an important role in regulating intestinal motility and its expression is a diagnostic hallmark of gastrointestinal stromal tumors (GIST). Data on a possible role of DOG1 in pancreatic cancer are rare and controversial. The aim of our study was to clarify the prevalence of DOG1 expression in pancreatic cancer and to study its association with parameters of cancer aggressiveness.

Methods. DOG1 expression was analyzed by immunohistochemistry in 599 pancreatic cancers in a tissue microarray format and in 12 cases of pancreatitis on large tissue sections.

Results. DOG1 expression was always absent in normal pancreas but a focal weak expression was seen in 4 of 12 cases of pancreatitis. DOG1 expression was, however, common in pancreatic cancer. Membranous and cytoplasmic DOG1 expression in tumor cells was highest in pancreatic ductal adenocarcinomas (61\% of 444 interpretable cases), followed by cancers of the ampulla Vateri (43\% of 51 interpretable cases), and absent in 6 acinus cell carcinomas. DOG1 expression in tumor associated stroma cells was seen in 76 of 444 (17\%) pancreatic ductal adenocarcinomas and in 7 of $51(14 \%)$ cancers of the ampulla Vateri. Both tumoral and stromal DOG1 expression were unrelated to tumor stage, grade, lymph node and distant metastasis, mismatch repair protein deficiency and the density of CD8 positive cytotoxic T-lymphocytes in the subgroups of ductal adenocarcinomas and cancers of ampulla Vateri. Overall, the results of our study indicate that DOG1 may represent a potential biomarker for pancreatic cancer diagnosis and a putative therapeutic target in pancreatic cancer. However, DOG1 expression is unrelated to pancreatic cancer aggressiveness.

\section{Introduction}

Pancreatic cancer is the 11th most frequent cancer, but the 2nd leading cause of cancer-related mortality in the United States of America (1). Both the incidence and mortality are continuously rising (2). The poor prognosis of pancreatic cancer results from the scarcity of early symptoms and consecutively a late diagnosis of locally advanced or metastatic cancers in most patients. The 5year survival independent of the tumor stage remains at $8 \%$ (3). The histopathological diagnosis of pancreatic cancer can be challenging due to the often limited quantity of cells or tissue obtainable by fine needle aspiration/biopsy and considerable inflammation in the surroundings of _. these cancers (4). 
63

64 DOG1 (Discovered On Gastrointestinal Stromal Tumors Protein 1), also known as 65 Transmembrane Protein 16A (TMEM16A) or Anoctamin-1 (ANO1) is a voltage-gated calcium66 activated chloride and bicarbonate channel $(5,6)$. DOG1 is highly expressed in the gastrointestinal 67 interstitial cells of Cajal, where it plays an important role in epithelial chloride secretion mediating 68 intestinal motility $(7,8)$. Calcium-activated chloride channel blocking drugs like niflumic acid

69 70 71

72 73 74 75 76 77 78 79 80 have been shown to block slow waves (pacemaker activity) - which produce motility - in the human small intestine and stomach (9). High levels of DOG1 expression are a diagnostic hallmark of gastrointestinal stromal tumor (GIST), a tumor derived from these cells (7, 10-12). However, DOG1 expression was also reported to occur in squamous cell carcinomas of the esophagus and head and neck, thyroid carcinomas, and adenocarcinomas of endometrium, stomach and colon (7, 13-16). Data on the prevalence and significance of DOG1 expression in pancreatic cancer are limited and partly controversial. In a study employing immunohistochemistry (IHC) on a tissue microarray (TMA), Hemminger et al (17) identified patchy low to moderate intensity DOG1 immunostaining in $8(7 \%)$ of 112 pancreatic adenocarcinomas. In contrast, Crottès et al (18) scrutinized available databases for signs of up-regulation of DOG1 protein and mRNA in pancreatic adenocarcinoma and determined that DOG1 is up-regulated in $75 \%$ of pancreatic carcinomas. From data derived from the TCGA database, these authors further concluded that high levels of DOG1 were correlated with low patient survival probability. Evidence for a functionally active role of DOG1 in pancreatic cancer cells come from four previous studies showing elevated DOG1 expression in pancreatic cancer cell lines and demonstrating that inhibition, knockdown or knockout of DOG1 attenuates cell motility, migration, and proliferation and promotes cell cycle arrest in G0/G1 phase in vitro and in vivo (18-21). Nielsen et al (22) described DOG1 expression to also occur in pancreatic cancer associated fibroblasts. In a thorough study analyzing DOG1 expression in well-defined stroma compartments of 8 pancreatic adenocarcinomas they found a higher rate of DOG1 expression in cancer-associated fibroblasts (CAFs) that were located in the immediate neighborhood of cancer cells (juxtatumoral stroma) than in the cancer periphery (peritumoral stroma).

The aims of this study were to clarify the prevalence of DOG1 expression in epithelial and stromal cells of pancreatic carcinomas and to identify potential associations with parameters of cancer 
94 aggressiveness. For this purpose, a cohort of 599 pancreatic carcinomas was analyzed for DOG1

95

96

97

98

99

100

101

102

103

104

105

106

107

108

109

110

111

112

113

114

115

116

117

118

119

120

121

122

123

124

expression by IHC in a TMA format.

\section{Materials \& Methods}

Tissue microarray. The 599 samples were diagnosed at the Institute of Pathology, University Medical Center Hamburg-Eppendorf, Hamburg, Germany: 532 ductal adenocarcinomas, 61 adenocarcinomas of the ampulla Vateri, and 6 acinar cell carcinomas. The TMA was made as described in (23). Clinico-pathological parameters were obtained from the pathology reports (Table 1). The molecular database attached to the TMA contained results on mismatch repair deficiency (dMMR, surrogate for microsatellite instability, MSI) measured by MLH1, MSH2, PMS2, and MSH6 immunohistochemistry in 519 cases from a previous study (24) and the density of CD8 positive cytotoxic T-lymphocytes in 599 cases (25). Large sections from 12 pancreatectomy specimens from patients with pancreatitis not suffering from carcinoma were also analyzed. The use of archived material for research purpose as well as patient data analysis has been approved by local laws (HmbKHG, §12) and by the ethics committee of Hamburg (WF049/09). The work was done in compliance with the Helsinki Declaration.

Immunohistochemistry. TMA sections were freshly cut, processed and stained the same day. Slides were deparaffinized with xylol, rehydrated and exposed to heat-induced antigen retrieval. Endogenous peroxidase activity was blocked with Dako Peroxidase Blocking Solution (Agilent, CA, USA; \#52023) for 10 minutes. Anti-DOG1 mouse monoclonal antibody MSVA201M (MS Validated Antibodies, Hamburg, Germany) was applied at 37 C, $60 \mathrm{~min}$, at 1:150. Staining was visualized with the EnVision Kit (Agilent, CA, USA; \#K5007) and counterstained with Haemalaun. DOG1 staining was predominantly membranous in pancreatic cancer cells. Scoring of the staining intensity was semi-quantitatively assessed as previously described in Juhnke 2017 (26). Specifically four grades were defined: Negative (no staining at all), weak (staining intensity of $1+$ in $\leq 70 \%$ of the tumor cells or staining intensity of $2+$ in $\leq 30 \%$ of the tumor cells), moderate (staining intensity of $1+$ in $>70 \%$ of the tumor cells, staining intensity of $2+$ in $>30 \%$ but in $\leq 70 \%$ of the tumor cells or staining intensity of $3+$ in $\leq 30 \%$ of the tumor 
125 cells), strong (staining intensity of $2+$ in $>70 \%$ of the tumor cells or staining intensity of $3+$ in $>$ $12630 \%$ of the tumor cells).

127

128

129

130

131

132

133

134

135

136

137

138

139

140

141

142

143

144

145

146

147

148

149

150

151

152

153

154

155

156

Statistics. JMP ${ }^{\circledR}$ software (SAS Institute Inc., NC, USA) was used for contingency tables and chi ${ }^{2}$ tests to search for associations between DOG1 expression and histological subtypes, clinicopathological parameters and dMMR. A p-value $\leq 0.05$ was considered as statistically significant.

\section{Results}

Technical issues. On our TMA, 501 of 599 (83.6\%) pancreatic cancers were analyzable in the DOG1 IHC analysis. Reasons for non-informative cases $(n=98,16.4 \%)$ included lack of tissue samples or absence of unequivocal cancer tissue in the TMA spot.

DOG1 expression in pancreatic cancers. DOG1 immunostaining could be observed in both cancer cells and in tumor associated stromal cells. A predominantly membranous cancer cell staining was seen in 294 (58.7\%) of the 501 interpretable cancers. The observed staining pattern were variable and ranged from focal staining of various intensity to intense diffuse positivity. Stroma cell staining was often periglandular or "juxtatumoral" but did also involve cells that were more remote from cancer cells. Representative images are shown in Figure 1. The frequency of DOG1 positive cancer cell staining was highest in ductal adenocarcinomas $(61.3 \%$; $n=444)$, followed by adenocarcinomas of the ampulla of Vateri $(43.1 \%$; $=51)$. DOG1 positive stromal cells were found in 76 of $444(17.1 \%)$ ductal adenocarcinomas, and 7 of 51 (13.7\%) adenocarcinomas of the ampulla of Vateri. DOG1 immunostaining both tumoral and stromal was absent in acinar cell carcinoma $(n=6)$. DOG1 staining was also completely absent in normal pancreatic cells. A weak to moderate focal DOG1 staining was seen, however, in 4 of 12 large sections of pancreatitis cases. Statistical associations were not observed between both stromal and tumor cell DOG1 staining and clinico-pathological parameters in the analysis of ductal adenocarcinomas of the pancreas ( $\mathrm{p}>0.1$ each; Table 2, Table 3) and of cancers of the ampulla Vateri ( $p>0.5$ each except of $p$ with $p=0.0104$; Table 2, Table 3). DOG1 staining was also 
157 unrelated to dMMR and the density of CD8 positive lymphocytes in ductal adenocarcinomas and 158 adenocarcinomas of the ampulla of Vateri ( $\mathrm{p} \geq 0.1$; Table 2, Table 3, and Table 4).

\section{Discussion}

160 The results of our study demonstrate that tumoral DOG1 expression is frequent in both ductal 161 adenocarcinoma of the pancreas (61.3\% of 444 cancers) and adenocarcinomas of the ampulla 162 Vateri (43.1\% of 51 cancers). This observation is consistent with data derived from large databases 163 on RNA and protein expression in cancers. Crottès et al (18) had scrutinized available databases 164 for signs of up-regulation of DOG1 mRNA and protein expression in pancreatic adenocarcinoma 165 and determined that DOG1 was up-regulated in $75 \%$ of pancreatic cancers. Our frequency of 166 tumoral DOG1 immunostaining in pancreatic cancer is markedly higher than in the only previous study investigating DOG1 expression by IHC. In a study analyzing 112 pancreatic adenocarcinomas in a TMA format, Hemminger et al (17) found a weak to moderate DOG1 positivity in $8(7 \%)$ of all carcinomas. The use of different antibodies, staining protocols, and criteria for defining positivity are the most common causes for different outcomes of studies employing IHC (27). In addition, in case of TMA studies, the time span between the cutting of the TMA section and its immunohistochemical staining has a marked impact on the staining intensity of many antibodies. Even a slide age of two weeks can lead to a marked reduction of staining (28).

Beside the expression of DOG1 in tumor cells, Nielsen et al. (29) have recently shown that DOG1 can also be expressed in CAFs. In their study, Nielsen et al focused on the analysis of the tumor microenvironment - especially the juxtatumoral, peripheral, lobular, septal, peripancreatic, and regressive stroma compartments - of chemotherapy-naïve (CTN-PC; n=10) and neoadjuvant treated (NAT-PC; $n=10$ ) pancreatic adenocarcinomas and found that DOG1 was particularly overexpressed in CAFs that were located in close contact to cancer cells (juxtatumoral CAFs). The authors concluded from their data that juxtatumoral CAFs characterized by strong DOG1 expression and several other markers might promote the proliferation and invasion of cancer cells. A pathogenetic role of DOG1 expression in CAFs is potentially also supported by our data, as DOG1 expressing fibroblasts were seen in $17 \%$ of pancreatic adenocarcinomas but neither in normal pancreas nor in chronic pancreatitis. That DOG1 expression in tumor or stromal cells did not show any associations with tumor stage, grade, or nodal and distant metastasis in our study argues against a clinically significant impact of 
188 DOG1 expression on pancreatic cancer aggressiveness. This is in contrast with data derived from 189 Crottès et al. from the TCGA database, where high levels of TMEM16A were linked to a low 190 patient survival probability in a cohort of 146 patients (18). Comparing protein expression 191 measured by IHC and RNA expression data is particularly challenging in pancreatic cancer 192 because of the high average stroma content of this tumor (30). RNA data may therefore be highly 193 diluted in many of pancreatic cancers and partly reflect tumor cell density. Moreover, if cancers 194 are preselected for high tumor cell content, a selection bias may apply. It may well be that 195 associations between molecular drivers of cancer aggressiveness and unfavorable tumor features 196 are - due to their overall very poor prognosis - particularly difficult to identify in pancreatic cancer. 197 That the density of CD8 positive cytotoxic T-lymphocytes did not vary between tumors expressing 198 different levels of DOG1 argues against a particular role of DOG1 in the extent of tumor 199 immunogenicity or pathways with a function in immune response.

200 Due to the general role of DOG1 overexpression in tumorigenesis and progression as well as the 201 absence or low level of DOG1 expression in most normal tissues, DOG1 may also represent a 202 suitable drug target. Studies have shown that partial or total inhibition of DOG1 with T16Ainh203 A01 and CaCCinh-A01 leads to reduced channel activity, cell viability, cell proliferation, cell 204 migration, increased apoptosis, and cell cycle arrest in G0/G1 phase in GIST and cancer cells of 205 the breast, bladder, head and neck, and esophagus in vitro (31-35) and reduced tumor growth of 206 lung, breast, and head and neck carcinomas in vivo $(36,37)$. In addition, three studies showed that 207 combined inhibition of DOG1 and EGFR or DOG1 and HER2 leads to reduced cell growth in a 208 cooperative manner and that DOG1 inhibition can reverse resistance to EGFR or HER2 therapies 209 in vitro and in vivo (37-39). Overall, this shows that DOG1 is a promising candidate for a new 210 target cancer therapy. Especially in pancreatic cancer, this deadly tumor entity with only a few 211 therapy options and a high frequency of DOG1 expression.

212

213 The data from this study also suggest a potential diagnostic utility of DOG1 IHC in pancreatic 214 cancer. Since DOG1 expression was detectable in more than 60\% of pancreatic adenocarcinomas 215 and $>40 \%$ of adenocarcinomas of the ampulla Vateri, but completely absent in normal pancreatic 216 tissues, a positive DOG1 immunostaining in a pancreatic biopsy may serve as an argument for 217 malignancy. It is of note, however, that DOG1 expression alone cannot secure a diagnosis of 218 pancreatic cancer as weak to moderate focal DOG1 immunostaining was also observed in 4 of 12 
219 pancreatitis specimens in our study. Current panels that are used to support the diagnosis of 220 malignancy in pancreatic biopsies typically include CA19-9, CK7, CK19, MUC1, and CEA, (40) 221 and could be complemented by DOG1.

222

223

\section{Conclusions}

224

In summary, the results of this study show that DOG1 is frequently expressed in pancreatic

225 adenocarcinoma. Although DOG1 expression is unrelated to parameters of cancer aggressiveness, it may be a suitable diagnostic marker and an excellent therapeutic target in pancreatic cancer.

227

228

229

230

231

232

233

234

235

236

237

238

239

240

241

242

243

244

245

246

247 248

249

\section{Acknowledgements}

We are grateful to Melanie Witt, Inge Brandt, Maren Eisenberg, and Sünje Seekamp for excellent technical assistance.

\section{Conflict of interest}

The DOG1 antibody clone MSVA-201M was received from MS Validated Antibodies GmbH (owned by a family member of GS).

\section{References}

1. Global cancer observatory: cancer today [Internet]. International Agency for Research on Cancer. [cited 28 October 2020].

2. Rahib L, Smith BD, Aizenberg R, Rosenzweig AB, Fleshman JM, Matrisian LM. Projecting cancer incidence and deaths to 2030: the unexpected burden of thyroid, liver, and pancreas cancers in the United States. Cancer Res. 2014;74(11):2913-21.

3. Siegel RL, Miller KD, Jemal A. Cancer Statistics, 2017. CA Cancer J Clin. 2017;67(1):730 .

4. Mangiavillano B, Sosa-Valencia L, Deprez P, Eisendrath P, Robles-Medranda C, Eusebi LH, Di Leo M, Auriemma F, Bianchetti M, Anderloni A, Carrara S, Repici A. Tissue acquisition and pancreatic masses: Which needle and which acquisition technique should be used? Endosc Int Open. 2020;8(10):E1315-E20. 
253 5. Caputo A, Caci E, Ferrera L, Pedemonte N, Barsanti C, Sondo E, Pfeffer U, Ravazzolo R, 254 Zegarra-Moran O, Galietta LJ. TMEM16A, a membrane protein associated with calcium255 dependent chloride channel activity. Science. 2008;322(5901):590-4.

256

257

258

259

260

261

262

263

264

265

266

267

268

269

270

271

272

273

274

275

276

277

278

279

280

281

282

283

284

285

286

287

288

6. Yang YD, Cho H, Koo JY, Tak MH, Cho Y, Shim WS, Park SP, Lee J, Lee B, Kim BM, Raouf R, Shin YK, Oh U. TMEM16A confers receptor-activated calcium-dependent chloride conductance. Nature. 2008;455(7217):1210-5.

7. Miettinen M, Wang ZF, Lasota J. DOG1 antibody in the differential diagnosis of gastrointestinal stromal tumors: a study of 1840 cases. Am J Surg Pathol. 2009;33(9):1401-8.

8. Chevalier NR, Ammouche Y, Gomis A, Teyssaire C, de Santa Barbara P, Faure S. Shifting into high gear: how interstitial cells of Cajal change the motility pattern of the developing intestine. Am J Physiol Gastrointest Liver Physiol. 2020;319(4):G519-G28.

9. Hwang SJ, Blair PJ, Britton FC, O'Driscoll KE, Hennig G, Bayguinov YR, Rock JR, Harfe BD, Sanders KM, Ward SM. Expression of anoctamin 1/TMEM16A by interstitial cells of Cajal is fundamental for slow wave activity in gastrointestinal muscles. J Physiol. 2009;587(Pt 20):4887904.

10. West RB, Corless CL, Chen X, Rubin BP, Subramanian S, Montgomery K, Zhu S, Ball CA, Nielsen TO, Patel R, Goldblum JR, Brown PO, Heinrich MC, van de Rijn M. The novel marker, DOG1, is expressed ubiquitously in gastrointestinal stromal tumors irrespective of KIT or PDGFRA mutation status. Am J Pathol. 2004;165(1):107-13.

11. Kindblom LG, Remotti HE, Aldenborg F, Meis-Kindblom JM. Gastrointestinal pacemaker cell tumor (GIPACT): gastrointestinal stromal tumors show phenotypic characteristics of the interstitial cells of Cajal. Am J Pathol. 1998;152(5):1259-69.

12. Sircar K, Hewlett BR, Huizinga JD, Chorneyko K, Berezin I, Riddell RH. Interstitial cells of Cajal as precursors of gastrointestinal stromal tumors. Am J Surg Pathol. 1999;23(4):377-89.

13. Friedrich RE, Wunder T, Schumacher U, Bartel-Friedrich S, Zustin J. Expression of DOG1 (Using SP31) in Poorly Differentiated Carcinoma of the Head and Neck. Anticancer Res. 2016;36(6):3117-22.

14. Chenevert J, Duvvuri U, Chiosea S, Dacic S, Cieply K, Kim J, Shiwarski D, Seethala RR. DOG1: a novel marker of salivary acinar and intercalated duct differentiation. Mod Pathol. 2012;25(7):919-29.

15. Hemminger J, Iwenofu OH. Discovered on gastrointestinal stromal tumours 1 (DOG1) expression in non-gastrointestinal stromal tumour (GIST) neoplasms. Histopathology. 2012;61(2):170-7.

16. Yu Y, Cao J, Wu W, Zhu Q, Tang Y, Zhu C, Dai J, Li Z, Wang J, Xue L, Zhen F, Liu J, Huang C, Zhao F, Zhou Y, Wen W, Pan X, Wei H, Zhu Y, He Y, Que J, Wang W, Luo J, Xu J, Chen L. Genome-wide copy number variation analysis identified ANO1 as a novel oncogene and

Peer) reviewing PDF | (2021:03:59486:1:1:NEW 10 Jun 2021) 
289

290

291

292

293

294

295

296

297

298

299

300

301

302

303

304

305

306

307

308

309

310

311

312

313

314

315

316

317

318

319

320

321

322

323

324

prognostic biomarker in esophageal squamous cell cancer. Carcinogenesis. 2019;40(10):1198208.

17. Hemminger J, Marsh WL, Iwenofu OH, Frankel WL. DOG1 (clone K9) is seldom expressed and not useful in the evaluation of pancreatic neoplasms. Appl Immunohistochem Mol Morphol. 2012;20(4):397-401.

18. Crottes D, Lin YT, Peters CJ, Gilchrist JM, Wiita AP, Jan YN, Jan LY. TMEM16A controls EGF-induced calcium signaling implicated in pancreatic cancer prognosis. Proc Natl Acad Sci U S A. 2019;116(26):13026-35.

19. Sauter DRP, Novak I, Pedersen SF, Larsen EH, Hoffmann EK. ANO1 (TMEM16A) in pancreatic ductal adenocarcinoma (PDAC). Pflugers Arch. 2015;467(7):1495-508.

20. Stanich JE, Gibbons SJ, Eisenman ST, Bardsley MR, Rock JR, Harfe BD, Ordog T, Farrugia G. Anol as a regulator of proliferation. Am J Physiol Gastrointest Liver Physiol. 2011;301(6):G1044-51.

21. Mazzone A, Eisenman ST, Strege PR, Yao Z, Ordog T, Gibbons SJ, Farrugia G. Inhibition of cell proliferation by a selective inhibitor of the $\mathrm{Ca}(2+)$-activated $\mathrm{Cl}(-)$ channel, Ano1. Biochem Biophys Res Commun. 2012;427(2):248-53.

22. Nielsen MFB, Mortensen MB, Detlefsen S. Typing of pancreatic cancer-associated fibroblasts identifies different subpopulations. World J Gastroenterol. 2018;24(41):4663-78.

23. Kononen J, Bubendorf L, Kallioniemi A, Barlund M, Schraml P, Leighton S, Torhorst J, Mihatsch MJ, Sauter G, Kallioniemi OP. Tissue microarrays for high-throughput molecular profiling of tumor specimens. Nat Med. 1998;4(7):844-7.

24. Fraune C, Burandt E, Simon R, Hube-Magg C, Makrypidi-Fraune G, Kluth M, Buscheck F, Hoflmayer D, Blessin NC, Mandelkow T, Li W, Perez D, Izbicki JR, Wilczak W, Sauter G, Schrader J, Neipp M, Mofid H, Daniels T, Isbert C, Clauditz TS, Steurer S. MMR Deficiency is Homogeneous in Pancreatic Carcinoma and Associated with High Density of Cd8-Positive Lymphocytes. Ann Surg Oncol. 2020.

25. Blessin NC, Li W, Mandelkow T, Jansen HL, Yang C, Raedler JB, Simon R, Büscheck F, Dum D, Luebke AM, Hinsch A, Möller K, Menz A, Bernreuther C, Lebok P, Clauditz T, Sauter G, Marx A, Uhlig R, Wilczak W, Minner S, Krech T, Fraune C, Höflmayer D, Burandt E, Steurer S. Prognostic role of proliferating CD8+ cytotoxic T-cells in human cancers. Clinical \& Translational Immunology. 2020; under review.

26. Juhnke M, Heumann A, Chirico V, Höflmayer D, Menz A, Hinsch A, Hube-Magg C, Kluth M, Lang DS, Möller-Koop C, Sauter G, Simon R, Beyer B, Pompe R, Thederan I, Schlomm T, Luebke AM. Apurinic/apyrimidinic endonuclease 1 (APE1/Ref-1) overexpression is an independent prognostic marker in prostate cancer without TMPRSS2:ERG fusion. Molecular carcinogenesis. 2017;56(9):2135-45. 
325

326

327

328

329

330

331

332

333

334

335

336

337

338

339

340

341

342

343

344

345

346

347

348

349

350

351

352

353

354

355

356

357

358

359

27. Janardhan KS, Jensen H, Clayton NP, Herbert RA. Immunohistochemistry in Investigative and Toxicologic Pathology. Toxicol Pathol. 2018;46(5):488-510.

28. Mirlacher M, Kasper M, Storz M, Knecht Y, Durmuller U, Simon R, Mihatsch MJ, Sauter G. Influence of slide aging on results of translational research studies using immunohistochemistry. Mod Pathol. 2004;17(11):1414-20.

29. Nielsen MFB, Mortensen MB, Sorensen MD, Wirenfeldt M, Kristensen BW, Schroder HD, Pfeiffer P, Detlefsen S. Spatial and phenotypic characterization of pancreatic cancerassociated fibroblasts after neoadjuvant treatment. Histol Histopathol. 2020;35(8):811-25.

30. Feig C, Gopinathan A, Neesse A, Chan DS, Cook N, Tuveson DA. The pancreas cancer microenvironment. Clin Cancer Res. 2012;18(16):4266-76.

31. Frobom R, Sellberg F, Xu C, Zhao A, Larsson C, Lui WO, Nilsson IL, Berglund E, Branstrom R. Biochemical Inhibition of DOG1/TMEM16A Achieves Antitumoral Effects in Human Gastrointestinal Stromal Tumor Cells In Vitro. Anticancer Res. 2019;39(7):3433-42.

32. Guan L, Song Y, Gao J, Gao J, Wang K. Inhibition of calcium-activated chloride channel ANO1 suppresses proliferation and induces apoptosis of epithelium originated cancer cells. Oncotarget. 2016;7(48):78619-30.

33. Berglund E, Akcakaya P, Berglund D, Karlsson F, Vukojevic V, Lee L, Bogdanovic D, Lui WO, Larsson C, Zedenius J, Frobom R, Branstrom R. Functional role of the $\mathrm{Ca}(2)(+)$-activated $\mathrm{Cl}(-)$ channel DOG1/TMEM16A in gastrointestinal stromal tumor cells. Exp Cell Res. 2014;326(2):315-25.

34. Duvvuri U, Shiwarski DJ, Xiao D, Bertrand C, Huang X, Edinger RS, Rock JR, Harfe BD, Henson BJ, Kunzelmann K, Schreiber R, Seethala RS, Egloff AM, Chen X, Lui VW, Grandis JR, Gollin SM. TMEM16A induces MAPK and contributes directly to tumorigenesis and cancer progression. Cancer Res. 2012;72(13):3270-81.

35. Britschgi A, Bill A, Brinkhaus H, Rothwell C, Clay I, Duss S, Rebhan M, Raman P, Guy CT, Wetzel K, George E, Popa MO, Lilley S, Choudhury H, Gosling M, Wang L, Fitzgerald S, Borawski J, Baffoe J, Labow M, Gaither LA, Bentires-Alj M. Calcium-activated chloride channel ANO1 promotes breast cancer progression by activating EGFR and CAMK signaling. Proc Natl Acad Sci U S A. 2013;110(11):E1026-34.

36. Hu C, Zhang R, Jiang D. TMEM16A as a Potential Biomarker in the Diagnosis and Prognosis of Lung Cancer. Arch Iran Med. 2019;22(1):32-8.

37. Kulkarni S, Bill A, Godse NR, Khan NI, Kass JI, Steehler K, Kemp C, Davis K, Bertrand CA, Vyas AR, Holt DE, Grandis JR, Gaither LA, Duvvuri U. TMEM16A/ANO1 suppression improves response to antibody-mediated targeted therapy of EGFR and HER2/ERBB2. Genes Chromosomes Cancer. 2017;56(6):460-71. 
360 38. Fujimoto M, Inoue T, Kito H, Niwa S, Suzuki T, Muraki K, Ohya S. Transcriptional 361 repression of HER2 by ANO1 Cl- channel inhibition in human breast cancer cells with resistance 362 to trastuzumab. Biochemical and Biophysical Research Communications. 2017;482(1):188-94.

363 39. Bill A, Gutierrez A, Kulkarni S, Kemp C, Bonenfant D, Voshol H, Duvvuri U, Gaither LA. 364 ANO1/TMEM16A interacts with EGFR and correlates with sensitivity to EGFR-targeting therapy 365 in head and neck cancer. Oncotarget. 2015;6(11):9173-88.

366 40. Wong HH, Chu P. Immunohistochemical features of the gastrointestinal tract tumors. J 367 Gastrointest Oncol. 2012;3(3):262-84. 
Table $\mathbf{1}$ (on next page)

Patient cohort

Table 1. Patient cohort 
1 Table 1. Patient cohort

all tumors $(n=599)$

Tumor type

ductal adenocarcinoma

acinar cell carcinoma

adenocarcinoma of the ampulla Vaterii

Tumor stage

pT1

pT2

pT3

pT4

Grade

1

2

3

Lymph node status

pNO

$\mathrm{pN}+$

Distant metastasis

pM0

pM1

Surgical margin status

Ro

$\mathrm{R} 1$
$532(89 \%)$

$6(1 \%)$

$61(10 \%)$

$20(3 \%)$

$93(16 \%)$

$435(73 \%)$

49 (8\%)

$19(3 \%)$

$420(74 \%)$

$130(23 \%)$

$135(23 \%)$

$461(77 \%)$

$474(79 \%)$

$123(21 \%)$

324 (58\%)

$231(42 \%)$ 
Table 2 (on next page)

DOG1 immunostaining in cancer cells and cancer phenotype

Table 2. DOG1 immunostaining in cancer cells and cancer phenotype 
1 Table 2. DOG1 immunostaining in cancer cells and cancer phenotype

\begin{tabular}{|c|c|c|c|c|c|c|c|}
\hline & & $\begin{array}{c}n \\
\text { evaluable }\end{array}$ & $\begin{array}{c}\text { DOG1 im } \\
\text { negative } \\
(\%)\end{array}$ & $\begin{array}{c}\text { unostai } \\
\text { weak } \\
(\%) \\
\end{array}$ & $\begin{array}{l}\text { ing in cance } \\
\text { moderate } \\
(\%)\end{array}$ & $\begin{array}{l}\text { cells } \\
\text { strong } \\
(\%)\end{array}$ & p value \\
\hline $\begin{array}{c}\text { Ductal } \\
\text { adenocarcinomas }\end{array}$ & & 444 & 38.7 & 26.1 & 17.8 & 17.3 & \\
\hline \multirow[t]{3}{*}{ Tumor stage } & pT1 & 12 & 16.7 & 25 & 25 & 33.3 & \multirow{3}{*}{0.5262} \\
\hline & pT2 & 62 & 35.5 & 27.4 & 22.6 & 14.5 & \\
\hline & pT3-4 & 368 & 39.7 & 26.1 & 16.8 & 17.4 & \\
\hline \multirow[t]{3}{*}{ Grade } & 1 & 11 & 36.4 & 18.2 & 18.2 & 27.3 & \multirow{3}{*}{0.4193} \\
\hline & 2 & 317 & 40.1 & 25.2 & 18 & 16.7 & \\
\hline & 3 & 94 & 27.7 & 31.9 & 19.1 & 21.3 & \\
\hline \multirow[t]{2}{*}{ Lymph node status } & pNO & 89 & 44.9 & 23.6 & 15.7 & 15.7 & \multirow{2}{*}{0.5912} \\
\hline & $\mathrm{pN}+$ & 352 & 36.9 & 26.7 & 18.5 & 17.9 & \\
\hline \multirow{2}{*}{$\begin{array}{l}\text { Surgical margin } \\
\text { status }\end{array}$} & Ro & 219 & 37.4 & 23.3 & 19.2 & 20.1 & \multirow{2}{*}{0.1260} \\
\hline & $\mathrm{R} 1$ & 192 & 37.5 & 32.3 & 16.1 & 14.1 & \\
\hline \multirow[t]{2}{*}{ mismatch repair } & intact & 400 & 39.3 & 26 & 17 & 17.8 & \multirow{2}{*}{0.5187} \\
\hline & deficent & 3 & 33.3 & 0 & 33.3 & 33.3 & \\
\hline $\begin{array}{l}\text { adenocarcinoma of } \\
\text { the ampulla Vaterii }\end{array}$ & & 51 & 56.9 & 17.6 & 13.7 & 11.8 & \\
\hline \multirow[t]{3}{*}{ Tumor stage } & pT1 & 3 & 0 & 66.7 & 0 & 33.3 & \multirow{3}{*}{0.0104} \\
\hline & pT2 & 9 & 22.2 & 22.2 & 44.4 & 11.1 & \\
\hline & pT3-4 & 39 & 69.2 & 12.8 & 7.7 & 10.3 & \\
\hline \multirow[t]{3}{*}{ Grade } & 1 & 0 & - & - & - & - & \multirow{3}{*}{0.5299} \\
\hline & 2 & 33 & 54.5 & 18.2 & 18.2 & 9.1 & \\
\hline & 3 & 18 & 61.1 & 16.7 & 5.6 & 16.7 & \\
\hline \multirow[t]{2}{*}{ Lymph node status } & $\mathrm{pNO}$ & 11 & 45.5 & 18.2 & 36.4 & 0 & \multirow{2}{*}{0.0595} \\
\hline & $\mathrm{pN}+$ & 40 & 60 & 17.5 & 7.5 & 15 & \\
\hline \multirow[t]{2}{*}{$\begin{array}{l}\text { Surgical margin } \\
\text { status }\end{array}$} & Ro & 43 & 55.8 & 14 & 16.3 & 14 & \multirow{2}{*}{0.1841} \\
\hline & $\mathrm{R} 1$ & 7 & 71.4 & 28.6 & 0 & 0 & \\
\hline
\end{tabular}




\begin{tabular}{|c|c|c|c|c|c|c|c|}
\hline \multirow[t]{2}{*}{ mismatch repair } & intact & 48 & 56.3 & 18.8 & 12.5 & 12.5 & \\
\hline & deficent & 0 & - & - & - & - & \\
\hline
\end{tabular}

2 


\section{Table 3(on next page)}

DOG1 immunostaining in stroma cells and cancer phenotype

Table 3. DOG1 immunostaining in stroma cells and cancer phenotype 
1 Table 3. DOG1 immunostaining in stroma cells and cancer phenotype

\begin{tabular}{|c|c|c|c|c|c|}
\hline & & \multicolumn{4}{|c|}{ DOG1 immunostaining in stroma cells } \\
\hline & & n evaluable & negative (\%) & positive (\%) & $p$ value \\
\hline Ductal adenocarcinomas & & 444 & 82.9 & 17.1 & \\
\hline \multirow[t]{3}{*}{ Tumor stage } & pT1 & 12 & 91.7 & 8.3 & \multirow{3}{*}{0.4117} \\
\hline & pT2 & 62 & 87.1 & 12.9 & \\
\hline & pT3-4 & 368 & 82.1 & 17.9 & \\
\hline \multirow[t]{3}{*}{ Grade } & 1 & 11 & 81.8 & 18.2 & \multirow{3}{*}{0.8236} \\
\hline & 2 & 317 & 83.6 & 16.4 & \\
\hline & 3 & 94 & 80.9 & 19.2 & \\
\hline \multirow[t]{2}{*}{ Lymph node status } & pNO & 89 & 82.0 & 18.0 & \multirow{2}{*}{0.8359} \\
\hline & $\mathrm{pN}+$ & 352 & 83.0 & 17.1 & \\
\hline \multirow[t]{2}{*}{ Surgical margin status } & Ro & 219 & 81.3 & 18.7 & \multirow{2}{*}{0.4064} \\
\hline & $\mathrm{R} 1$ & 192 & 84.4 & 15.6 & \\
\hline \multirow[t]{2}{*}{ mismatch repair } & intact & 400 & 83.2 & 16.8 & \multirow{2}{*}{0.4885} \\
\hline & deficent & 3 & 66.7 & 33.3 & \\
\hline $\begin{array}{l}\text { adenocarcinoma of the } \\
\text { ampulla Vaterii }\end{array}$ & & 51 & 86.3 & 13.7 & \\
\hline \multirow[t]{3}{*}{ Tumor stage } & pT1 & 3 & 66.7 & 33.3 & \multirow{3}{*}{0.1748} \\
\hline & pT2 & 9 & 100.0 & 0.0 & \\
\hline & pT3-4 & 39 & 84.6 & 15.4 & \\
\hline \multirow[t]{3}{*}{ Grade } & 1 & 0 & - & - & \multirow{3}{*}{0.1825} \\
\hline & 2 & 33 & 81.8 & 18.2 & \\
\hline & 3 & 18 & 94.4 & 5.6 & \\
\hline \multirow[t]{2}{*}{ Lymph node status } & pNO & 11 & 81.8 & 18.2 & \multirow{2}{*}{0.6374} \\
\hline & $\mathrm{pN}+$ & 40 & 87.5 & 12.5 & \\
\hline \multirow[t]{2}{*}{ Surgical margin status } & Ro & 43 & 86.1 & 14.0 & \multirow{2}{*}{0.9813} \\
\hline & $\mathrm{R} 1$ & 7 & 85.7 & 14.3 & \\
\hline
\end{tabular}


mismatch repair

intact

deficent
48

0
84.8

15.2

2 
Table 4 (on next page)

DOG1 immunostaining and CD8 positivity

Table 4. DOG1 immunostaining and CD8 positivity 
1 Table 4. DOG1 immunostaining and CD8 positivity

2

\begin{tabular}{|c|c|c|c|c|}
\hline & $\begin{array}{c}\text { DOG1 in cancer } \\
\text { cells }\end{array}$ & n evaluable & $\begin{array}{l}\text { CD8 density } \\
(\text { cells/mm²) }\end{array}$ & $p$ value \\
\hline \multirow{4}{*}{ Ductal adenocarcinomas } & negative & 172 & $239.6 \pm 21.9$ & \multirow{4}{*}{0.7658} \\
\hline & weak & 116 & $226.0 \pm 26.7$ & \\
\hline & moderate & 79 & $197.8 \pm 32.4$ & \\
\hline & strong & 77 & $226.8 \pm 32.8$ & \\
\hline \multirow{5}{*}{$\begin{array}{c}\text { adenocarcinoma of the } \\
\text { ampulla Vaterii }\end{array}$} & negative & 29 & $291.1 \pm 78.8$ & \multirow{4}{*}{0.1048} \\
\hline & weak & 9 & $121.7 \pm 141.5$ & \\
\hline & moderate & 7 & $637.1 \pm 160.5$ & \\
\hline & strong & 6 & $179.6 \pm 173.3$ & \\
\hline & $\begin{array}{c}\text { DOG1 in stroma } \\
\text { cells }\end{array}$ & n evaluable & $\begin{array}{l}\text { CD8 density } \\
\left(\text { cells } / \mathrm{mm}^{2}\right)\end{array}$ & $p$ value \\
\hline \multirow{2}{*}{ Ductal adenocarcinomas } & negative & 368 & $227.7 \pm 15.0$ & \multirow{2}{*}{0.8326} \\
\hline & positive & 76 & $220.1 \pm 33.0$ & \\
\hline \multirow{2}{*}{$\begin{array}{c}\text { adenocarcinoma of the } \\
\text { ampulla Vaterii }\end{array}$} & negative & 44 & $318.4 \pm 66.3$ & \multirow{2}{*}{0.3577} \\
\hline & positive & 7 & $152.3 \pm 166.2$ & \\
\hline
\end{tabular}

3

4 
Figure 1

DOG1 immunostaining

Figure 1. DOG1 immunostaining. The panels A-D show DOG1 positive ductal adenocarcinomas with strong $(A)$, moderate $(B)$, focal moderate $(C)$, and weak immunostaining of tumor cells (D). The panels $A$ and $C$ also contain DOG1 negative normal ducts (arrow). The panels $E$ and $F$ show DOG1 negative cancers with diffuse $(E)$ and periductal DOG1 (F) staining of stromal cells (F). 

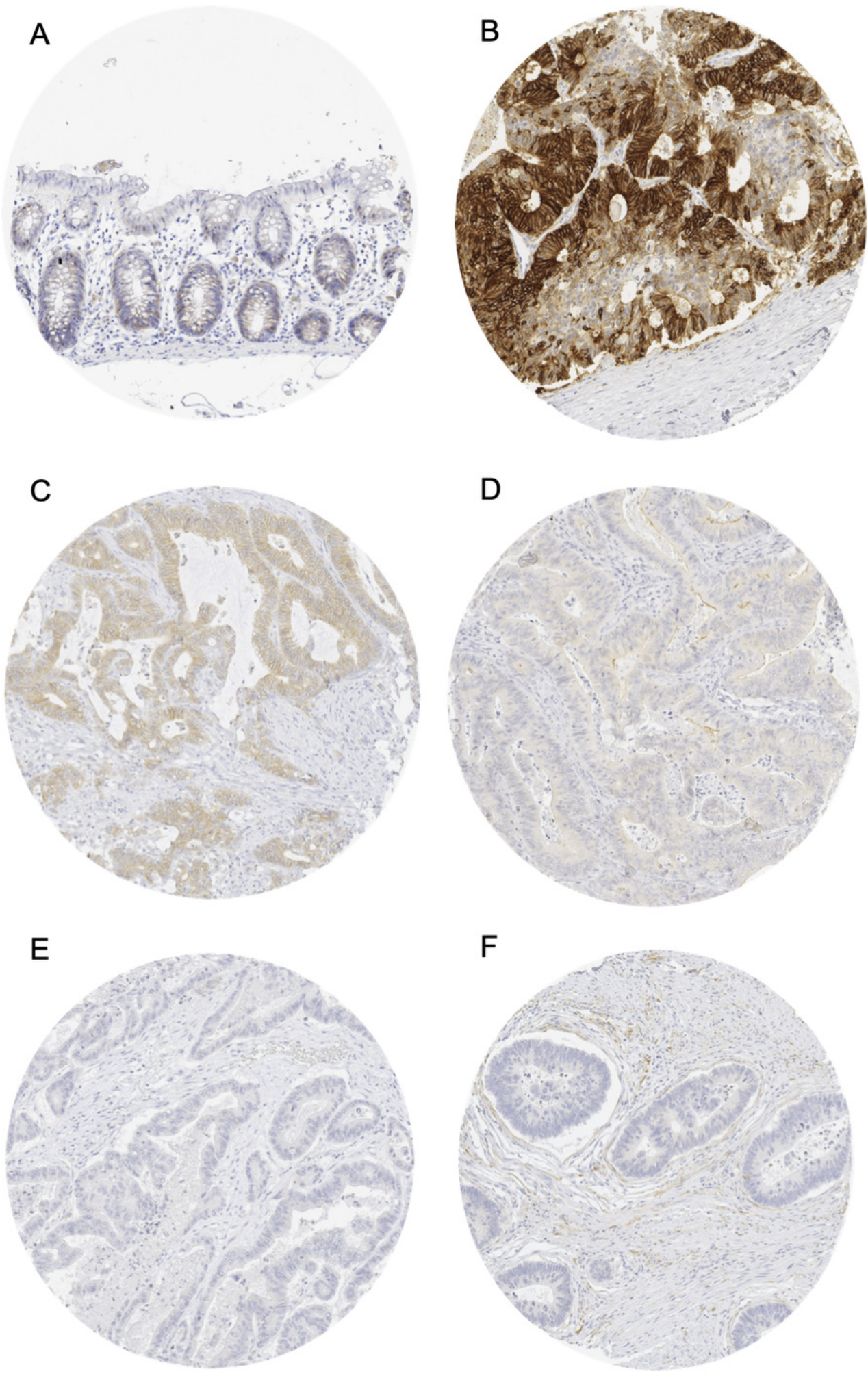